\title{
ACORDO DE PARIS: REFLEXÕES E DESAFIOS PARA O REGIME INTERNACIONAL DE MUDANÇAS CLIMÁTICAS
}

\author{
Fernando Cardozo Fernandes Rei \\ Doutor em Direito pela Universidad de Alicante (UA), pela Universidad Complutense de \\ Madrid (UCM) e pela Universidade de São Paulo (USP). \\ Professor do Programa de Pós-Graduação stricto sensu em Direito \\ da Universidade Católica de Santos (UNISANTOS). \\ E-mail: fernandorei@ig.com.br
}

\begin{tabular}{r|r}
\multicolumn{2}{c}{ Alcindo Fernandes Gonçalves } \\
\hline $\begin{array}{r}\text { Doutor e Mestre em Direito pela Universidade de São Paulo (USP). } \\
\text { Professor e Coordenador do Programa de Pós-Graduação stricto sensu em } \\
\text { Direito da Universidade Católica de Santos (UNISANTOS). } \\
\text { E-mail: alcindo@unisantos.br }\end{array}$ & \\
Luciano Pereira de Souza & \\
\hline Doutorando em Direito pela Universidade Católica de Santos (UNISANTOS). \\
Mestre em Direito pela Universidade de São Paulo (USP). \\
Professor da Universidade Santa Cecília (UNISANTA). \\
E-mail: proflucianosouza@terra.com.br
\end{tabular}

\section{RESUMO}

O objetivo do trabalho é apresentar os desafios que o regime internacional de mudanças climáticas pós-2015 traz a todos os países com relação às medidas de mitigação para atingir o objetivo definido no Acordo de Paris, bem como fazer uma reflexão quanto às contribuições determinadas unilateralmente pelos países - respeitadas suas capacidades e necessidades de desenvolvimento - e quanto ao efeito conjunto das reduções e remoções de gases de efeito estufa, avaliando se essas são suficientes para limitar o aquecimento global em até $2^{\circ} \mathrm{C}$. Para tanto, o trabalho inicia-se com uma reflexão sobre a contribuição brasileira ao novo período e avança, numa breve análise do contexto mundial e do futuro do regime. Partindo da visão de regimes internacionais como ações de governança, o trabalho realiza breve exame do regime de mudanças climáticas, com destaque para as inovações introduzidas pelo Acordo de Paris. O método utilizado para fazer a análise deste estudo será o analítico, com suporte em pesquisa teórica, tomando por base levantamentos bibliográficos e doutrinários em 
relação ao regime internacional e à governança global. $\mathrm{O}$ artigo conclui que a governança global do meio ambiente promoveu aplicação e evolução do princípio das responsabilidades comuns, porém diferenciadas no regime internacional de mudanças climáticas.

PALAVRAS-CHAVE: Acordo de Paris; Regime internacional de mudanças climáticas; Governança global do meio ambiente.

\title{
PARIS AGREEMENT: REFLECTIONS AND CHALLENGES FOR THE INTERNATIONAL CLIMATE CHANGE REGIME
}

\begin{abstract}
The objective of the paper is to present the challenges posed by the post2015 international climate change regime to all countries in relation to mitigation measures to achieve the goal set in the Paris Agreement and to reflect on the contributions determined unilaterally by the countries, respecting their capacities and development needs and on the combined effect of reductions and removals of greenhouse gases, if sufficient to limit global warming by up to $2^{\circ} \mathrm{C}$. Therefore, the work starts with a reflection on the Brazilian contribution to the new period and advances a brief analysis of the global context and the future of the regime. From the point of view of international regimes as governance actions, this paper briefly examines the climate change regime, highlighting the innovations introduced by the Paris Agreement. The method used to make the analysis of this study will be the analytical with support in theoretical research taking into account bibliographical and doctrinal surveys in relation to the international climate change regime and to global governance. The article concludes that the environmental global governance promoted implementation and evolution of the principle of common but differentiated responsibilities within the climate change regime.
\end{abstract}

Keywords: Paris Agreement; Climate change international regime; Global governance of the environment. 


\section{INTRODUÇÃO}

O regime internacional de mudanças climáticas, organizado no âmbito do Sistema das Nações Unidas há 24 anos, constitui, em essência, um arranjo institucional dinâmico e de construção permanente. Criado para facilitar o entendimento e promover a cooperação entre os 195 países signatários, é dotado de estrutura jurídica e organizacional próprias, que têm como objetivo ${ }^{1}$ estabilizar o sistema climático global e conter o aquecimento da temperatura do planeta, causado por emissões de gases de efeito estufa (GEE), como o dióxido de carbono proveniente da queima de combustíveis fósseis e do desmatamento e da degradação florestal decorrentes das mudanças de uso da terra para atividades agropecuárias e ocupação urbana.

A concretização desse impostergável objetivo, normatizado na Convenção-Quadrodas NaçõesUnidassobreMudançasClimáticas, entrelaça o regime climático com a governança global ambiental, como mecanismo para a solução dos conflitos e a promoção da necessária cooperação entre os Estados nacionais, no mundo globalizado, interdependente e cada vez mais complexo. A governança, como instrumento de participação ampliada, com envolvimento de atores estatais e não estatais, fundada no consenso e na persuasão para a elaboração da sua autorregulamentação e ancorada num arranjo institucional permanente (CAMARGO, 2015), constitui o caminho a ser percorrido para que possa concretizar tempestivamente esse objetivo de estabilização climática tempestivamente.

Justamente essa tem sido a preocupação de alguns estudiosos e a tônica de muitos questionamentos sobre a eficácia do regime de mudanças climáticas: o regime internacional constituído pelos Estados que, até a Conferência das Nações Unidas sobre as Mudanças Climáticas de 2015 (COP-21), tinham-se mostrado conservadores e mais aferrados ao princípio da soberania, a ponto de refrear o próprio desenvolvimento do regime climático - seria capaz de conduzir e induzir as necessárias ações (especialmente de reduções de emissões de GEE), a tempo de evitar uma ruptura do sistema climático global?

$\overline{1 \text { Conforme o art. } 2^{\circ}}$ da Convenção, promulgada pelo Decreto n. 652, de $1^{\text {o }}$ de julho de 1998 , "O objetivo final desta Convenção e de quaisquer instrumentos jurídicos com ela relacionados que adote a Conferência das Partes é o de alcançar, em conformidade com as disposições pertinentes desta Convenção, a estabilização das concentrações de gases de efeito estufa na atmosfera num nível que impeça uma interferência antrópica perigosa no sistema climático. Esse nível deverá ser alcançado num prazo suficiente, que permita aos ecossistemas adaptarem-se naturalmente à mudança do clima que assegure que a produção de alimentos não seja ameaçada e que permita ao desenvolvimento econômico prosseguir de maneira sustentável.” 
Nesse ponto, aplicam-se bem ao regime de combate às mudanças climáticas as palavras conclusivas de Camargo (2015, p. 92):

\begin{abstract}
A efetividade dos Regimes Internacionais enquanto ações de governança ambiental global depende da vontade do Estado-nação de abrir mão de alguns de seus dogmas para a consecução do interesse comum mundial, com plena transparência no monitoramento de suas condutas e do grau de resistência dos mecanismos propostos, e ajustados no âmbito interno de cada Estado-nação.
\end{abstract}

No âmbito do regime das mudanças climáticas, é possível divisar um mundo em dois blocos: um deles, formado por países que, predominantemente, são emissores de GEE, normalmente industrializados, com economias desenvolvidas ou em desenvolvimento e que sofrem menos ou não tão intensamente os efeitos das mudanças climáticas; e um segundo bloco, formado pelos países que estão sentindo mais os efeitos das mudanças do que contribuindo com emissões de GEE (FARIAS; REI, 2015, p. 119).

Qual foi a vontade dos Estados na COP-21? Em termos de normatização, de detalhamento das obrigações de cada país, de definição de metas quantificadas de redução, métrica para o cumprimento das metas de redução e dos necessários aportes financeiros que os países desenvolvidos farão para que os países em desenvolvimento possam atingir suas metas de redução e promover as necessárias adaptações às mudanças climáticas em curso, não se pode negar que o Acordo de Paris trouxe uma lufada de esperança ao regime. A comunidade internacional comprometeu-se a limitar a elevação da temperatura abaixo dos $2^{\circ} \mathrm{C}$ e a continuar os esforços para limitar o aumento da temperatura a $1,5^{\circ} \mathrm{C}$ (preâmbulo).

Como é cediço, o objetivo de um aquecimento máximo de $2^{\circ} \mathrm{C}$ em relação à era pré-industrial tinha sido definido em 2009, na COP de Copenhague, e ele implica uma redução drástica das emissões de gases de efeito estufa, com medidas como economia de energia, maiores investimentos em energias renováveis e reflorestamento.

Ainda na COP de Copenhague, os países desenvolvidos prometeram 100 bilhões de dólares por ano, a partir de 2020, com o fim de ajudar as nações em desenvolvimento a financiar a transição para energias limpas, assim como sua adaptação aos efeitos do aquecimento. Como foi defendido pelos países em desenvolvimento, o texto do Acordo de Paris, em seu item 54, estabelece que a soma de 100 bilhões de dólares por ano 
é apenas "um teto"; e que um novo valor financeiro será definido em 2025 (ACORDO DE PARIS, 2015, p. 8).

Se for certo que o contexto da agenda climática sugeria uma situação de tensão antes da COP-21, que levantava ao menos dois questionamentos, o primeiro relativo ao critério de distribuição das responsabilidades dos Estados em relação à adoção das medidas de mitigação, e o segundo, relativo à real capacidade de o multilateralismo tornar efetivos os esforços de mitigação e adaptação (REI; CUNHA, 2015, p. 21), o Acordo de Paris promoveu uma significativa mudança de tom.

Como se sabe, o regime climático fundamenta-se no princípio da responsabilidade comum, porém diferenciada, entre os países, que visa a distribuir com equidade a parcela de ônus, de obrigações que cada país deve suportar nas ações de mitigação, tendo em vista suas contribuições históricas de GEE (e por que não as suas contribuições atuais?), sua capacidade interna para realizar os esforços de mitigação e adaptação e ajudar outros países, sem prejuízo de seu direito ao desenvolvimento.

Nesse sentido, cabe ressaltar que "a distribuição de compromissos de mitigação de emissões de GEE entre os países tem-se revelado uma das principais questões de embate nas negociações internacionais sobre o regime climático" (REI; CUNHA, 2015, p. 34). E estava cada vez mais presente que países em desenvolvimento, notadamente a China, a Índia, o Brasil e a África do Sul, teriam que assumir suas responsabilidades com metas de redução de emissões, e não somente os do Anexo I da Convenção (entre os quais estão países desenvolvidos, membros da Organização para a Cooperação e Desenvolvimento Econômico (OCDE) e países da Europa Oriental em transição para economia de mercado). ${ }^{2}$ Dessa forma, o Acordo, em seu art. 4, item 4, estabelece que os países industriais devam estar na linha de frente e estabelecer objetivos de redução das emissões em valores absolutos, enquanto que os países em desenvolvimento deverão continuar a aumentar os esforços na luta contra o aquecimento global à luz de sua situação nacional.

As reflexões, desafios e oportunidades para o futuro do regime das mudanças climáticas desenvolvem-se a partir dessas condicionantes políticas, normativas, econômicas e culturais, como se poderá avaliar a seguir.

2 Aliás, ressalte-se que os EUA não assinaram o Protocolo de Quioto, pois têm mantido posição no sentido de que todos os países da Convenção devem comprometer-se com metas de redução, e não apenas os do Anexo I. 


\section{REFLEXÕES SOBRE A CONTRIBUIÇÃO DO BRASIL}

Em setembro de 2015, na contagem regressiva para a COP-21, o Governo Dilma Rousseff anunciou as metas de redução de emissões de GEE para levar à tão esperada COP da "virada" do regime de combate às mudanças climáticas.

O Brasil assume o compromisso de reduzir em $43 \%$ as emissões de GEE, tendo como referência o ano de 2005. A então presidente anuncia ainda, entre as medidas de mitigação, que o Brasil ${ }^{3}$ atingirá o desmatamento ilegal zero em 2030 (frise-se apenas o ilegal) e que irá restaurar algo em torno de 12 milhões de hectares, recuperar 15 milhões de hectares de pastagens degradadas e integrar e 5 milhões de hectares de lavourapecuária-florestas.

Entretanto, o Brasil (por meio do governo Dilma Rousseff) recusou-se a assinar a Declaração de Nova Iorque sobre Florestas, em setembro de 2014, que tinha como um de seus objetivos o desmatamento zero no mundo até 2030. Esqueceu-se também de que as metas de $\mathrm{Aichi}^{4}$ de Biodiversidade são mais ambiciosas; e que há metas específicas e mais próximas de redução do desmatamento dos $7 \%$ a $9 \%$ restantes da Mata Atlântica, por exemplo.

Esse compromisso é fácil de fazer, porém difícil de cumprir no cenário atual, que amargou um crescimento de $16 \%$ no desmatamento amazônico em 2014, com referência ao ano anterior; e atende às expectativas de atores internacionais (e nacionais) sobre as contribuições da "potência ambiental".

A Contribuição Nacionalmente Determinada (INDC, na sigla em

\footnotetext{
3 Numa ação paradiplomática diferenciada, os governos de Mato Grosso e do Acre assumem, no âmbito da COP-21, o compromisso de desmatamento ilegal zero até o ano de 2020. http://www.mt.gov. $\mathrm{br} /$-/governador-e-ministra-assinam-declaracao-de-esforcos-conjuntos-para-desmatamento-zero.

4 No processo de elaboração do Plano Estratégico de Biodiversidade 2011 - 2020, o Secretariado da Convenção sobre Diversidade Biológica (CDB) propôs que se estabelecesse um novo conjunto de metas, na forma de objetivos de longo prazo, que foram materializados em 20 proposições, todas voltadas à redução da perda da biodiversidade em âmbito mundial. Denominadas Metas de Aichi para a Biodiversidade, elas estão organizadas em cinco grandes objetivos estratégicos: tratar das causas fundamentais de perda de biodiversidade, fazendo com que as preocupações com a biodiversidade permeiem governo e sociedade; reduzir as pressões diretas sobre a biodiversidade e promover o uso sustentável; melhorar a situação da biodiversidade, protegendo ecossistemas, espécies e diversidade genética; aumentar os benefícios de biodiversidade e serviços ecossistêmicos para todos; e aumentar a implantação, por meio de planejamento participativo, da gestão de conhecimento e capacitação.
} 
inglês $)^{5}$ do Brasil $^{6}$ é anêmica em termos de ações concretas para atingir as metas de redução na área de uso do solo, de manejo e de conservação de florestas; e apresenta apenas propostas genéricas:

a) implementar atividades de Redução de Emissões de gases de efeito estufa provenientes do Desmatamento e da Degradação florestal, considerando o papel da conservação de estoques de carbono florestal, do manejo sustentável de florestas e do aumento de estoques de carbono florestal (REDD+), que ainda carece de desenvolvimentos e de patrocinadores;

b) reforçar e impor a implementação do Código Florestal em nível federal, estadual e local, sem apontar a forma;

c) ampliar sistemas de manejo sustentável de florestas nativas por meio de sistemas de georreferenciamento e rastreamento aplicáveis ao manejo de florestas nativas, com vistas ao combate de práticas ilegais e insustentáveis. Ou seja, nada de muito concreto, planejado e detalhado, deixando muitas dúvidas e incertezas.

Para tornar mais frágil a proposta brasileira, às vésperas da COP21 o Brasil foi atingido por devastador acidente poluidor de dimensões humanas, sociais e ecológicas nunca vistas na história do País, que foi o rompimento da barragem da Mineradora Samarco, em Mariana (MG). Esse acidente, a par das múltiplas responsabilidades do titular da atividade minerária e de seus administradores e controladores, coloca em questão, no plano internacional, a capacidade e a efetiva atuação do Estado em sede de controle e fiscalização das atividades causadoras de riscos e impactos ambientais, como a mineração.

O Brasil, que ocupou papel destacado e de liderança no primeiro período de negociações do regime, parece ter perdido seu protagonismo durante os últimos anos, ficando à margem das grandes decisões e articulações, em virtude da perda de prioridade da agenda ambiental no governo Dilma Rousseff.

5 As Intended National Determined Contributions (INDC), Contribuições Internacionais Nacionalmente Determinadas, consistem nas contribuições de redução que os países pretendem assumir, em caráter voluntário, a partir de 2015, e obrigatório, a partir de 2020, quando os países serão convidados a revê-las. "Assim como ocorreu na Emenda de Doha, as INDC podem ser estabelecidas por cada parte, conforme critérios por esta livremente definidos. Come explica o Center for Climate and Energy Solutions (2014), a formação das INDCs parte de uma abordagem bottom-up, segundo a qual é possível usar os mais diversos parâmetros, tais como: Metas absolutas de redução de emissões, ou fundadas na intensidade-carbono ou mesmo em emissões per capita; metas amplas para toda a economia (economy wide) ou setoriais; metas que adotam diferentes anos como base - 1990, 2000 ou projeções tendenciais; etc." (REI; CUNHA, 2015, p. 22).

6 BRASIL. Pretendida Contribuição Nacionalmente Determinada (INDC) Para Consecução do Objetivo da Convenção-Quadro das Nações Unidas sobre Mudança do Clima. Disponível em: http://www. itamaraty.gov.br/images/ed_desenvsust/BRASIL-iNDC-portugues.pdf. 
Uma questão que se apresenta ao atual governo é: qual será seu comportamento a partir da COP-22 no regime, especialmente se for capaz de concretizar promessas e metas de redução de emissões com as quais o Brasil se comprometeu?; e qual será o espaço para a participação dos governos subnacionais e locais, além de outros relevantes players da governança multinível, que podem dar sua valiosa contribuição?

\section{O CONTEXTO GLOBAL E O FUTURO DO REGIME}

O contexto global não se mostrava dos mais animadores para a agenda climática, que ainda corre o risco de esfriar completamente (mas a temperatura global vai continuar aumentando) antes da COP-21. Em pauta estavam, em primeiro plano, o combate ao terror desencadeado pelos atentados em Paris e nos EUA; e, de modo geral, a prioridade continuava sendo a segurança internacional, com as atenções voltadas para a Síria, o Iraque e o Estado Islâmico, além de outras agressões endêmicas. Também se destacavam a crise humanitária dos refugiados da África, da Síria, do Iraque e do Afeganistão, além de questões econômicas, como a queda acentuada do preço do petróleo, a desaceleração das trocas internacionais, e diplomáticas, como as tensões nas relações entre a Rússia e os países ocidentais por causa de sanções econômicas impostas pela União Europeia e pelos EUA, em razão da interferência russa na crise ucraniana.

Assim, era plausível considerar que a ordem de prioridades da agenda internacional não privilegiasse a pauta ambiental. Aliás, o Conselho de Segurança da ONU está longe de ser o foro adequado para tratar da questão ambiental, que deposita suas esperanças nos regimes ambientais e na governança adotada por eles, mas não na adoção de medidas de coercibilidade, que, certamente, vão esvaziar os regimes ambientais internacionais. Segundo More (201?),

\footnotetext{
o tratamento da questão ambiental sob os auspícios do princípio da segurança internacional coletiva adotado na Carta da Organização das Nações Unidas (ONU), confere à matéria denominada segurança ecológica, status de direito internacional de reconhecimento universal, cuja existência e medidas de coercibilidade passam à competência do Conselho de Segurança da ONU.
}

Mas o regime internacional de mudanças climáticas surpreendeu, persistindo e resistindo. Em termos de performance - como observado 
pelo consagrado estudioso de regimes Young (2010) - o regime precisava destravar-se se quisesse avançar com a agilidade necessária para adotar as decisões inadiáveis sobre o futuro da civilização pós-industrial no antropoceno. E deve-se destacar que o então modelo de negociações multilaterais amplas na Convenção-Quadro não tinha avançado no ritmo e na proporção necessários para deter o aquecimento global antropogênico (GONÇALVES, 2015).

Além disso, atitudes defensivas dos países-partes dificultavam avanços que pudessem trazerônus para os respectivos estados, especialmente aqueles relacionados com a eventual diminuição da atividade econômica para atingir metas de redução de GEE, como ressalta Gonçalves (2015).

Outros fatores também explicavam o insucesso do modelo de negociações multilaterais da Convenção-Quadro, tais como a necessidade de consenso para deliberar, a formação de acordos frágeis e instáveis, a apresentação de documentos vagos e genéricos, a falta de sanções nos tratados e a possibilidade de free-riders ${ }^{7}$ que se aproveitam do esforço alheio, além da vetusta e sempre presente divergência de fundo entre países desenvolvidos e em desenvolvimento (GONÇALVES, 2015).

Nessesentido, veioa calhara adoção deestratégiascomplementares às negociações multilaterais (GONÇALVES, 2015, p. 15-16): a) uso da estratégia "bottom-up", que consiste em concitar os países a refletir e a elaborar suas propostas em face das suas próprias realidades, para partir em direção à definição de metas globais; b) realização de negociações em blocos (bilaterais ou plurilaterais) para atingir o entendimento mais rapidamente, com menos participantes, e c) fortalecimento dos processos e mecanismos que envolvem a sociedade civil global nas negociações. Não se trata de negar o multilateralismo que constitui a base do regime atual, mas de propor novas formas - complementares - de fazer com que as decisões sejam tomadas em âmbito global. E foi, felizmente, o que se verificou.

O regime jurídico internacional de mudanças climáticas está juridicamente estruturado por quatro documentos: a Convenção-Quadro das Nações Unidas sobre Mudanças Climáticas (aprovada por ocasião da Rio/92, e que entrou em vigor em 1994); o Protocolo de Quioto (aprovado em 1997, que entrou em vigor em 2005 e encerrou seu primeiro período de redução de emissões em 2012); a Emenda Doha ao Protocolo (aprovada

\footnotetext{
7 Caronistas. (Tradução do autor)

8 De baixo para cima. (Tradução do autor)
} 
em 2013), que estabeleceu novos compromissos de redução dos países desenvolvidos para o segundo período do protocolo, e que, no entanto, até o momento, não entrou em vigor; e o Acordo de Paris (aprovado em 2015, na COP-21, e que entrou em vigor em 2016), conforme assinalam Rei e Cunha (2015).

Já o desenho organizacional do regime de combate às mudanças climáticas é formado pelos seguintes eixos temáticos: a) mitigação das mudanças climáticas; b) adaptação às mudanças climáticas; c) financiamento, tecnologia e capacitação; d) transparência; e) instrumentos econômicos e f) revisão periódica.

Para uma visão geral desses arranjos organizacionais, de suas incumbências e suas interconexões, bem como do andamento dos trabalhos no âmbito da Convenção-Quadro, é importante observar o resumo elaborado pelo Secretariado da Convenção, a pedido do Grupo de Trabalho ad hoc da Plataforma de Durban, que foi constituído em 2011, com a atribuição de desenvolver um protocolo, instrumento legal ou acordo que vincule todas as partes no âmbito da Convenção-Quadro, até 2015, para ser aprovado na $21^{\text {a }}$ Conferência das Partes; e que esse protocolo ou acordo legal possa ser implementado a partir de 2020, o que, efetivamente, acabou por acontecer.

Observam-se alguns arranjos no regime da Convenção-Quadro das Nações Unidas sobre a Mudança do Clima, que apontam para uma governança multinível, com participação dos atores subnacionais e não estatais. Destaque-se que o Acordo de Paris reconhece expressamente "a importância dos compromissos de todos os níveis de governo e de diferentes atores, de acordo com as respectivas legislações nacionais das partes, no combate às mudanças climáticas" (preâmbulo).

Embora não seja possível, por ora, firmar juridicamente acordos internacionais com grupos sociais (indígenas, povos das florestas), com organizações do terceiro setor e com agentes econômicos, é possível estabelecer compromissos políticos, como a Declaração de Nova Iorque sobre Florestas, assinada em 2014, por ocasião da Cúpula do Clima das Nações Unidas.

Em relação à eficiência do regime climático, um dos grandes desafios é formar, o mais rapidamente possível, consenso social global sobre os riscos das mudanças climáticas (aquecimento global, eventos climáticos extremos, acidificação dos oceanos, aumento do nível dos oceanos).

O trabalho de Hoffman (2015) sobre a questão cultural, que está 
por trás do debate a respeito das mudanças climáticas, mostra a divisão do povo norte-americano em relação ao tema, bem como a polarização da questão dentro da cena política, entre os conservadores e democratas; e fornece elementos que explicam muito bem por que os EUA não aderiram ao Protocolo de Quioto e continuam com um pé atrás na Convenção. Não obstante todas as expectativas geradas pelos compromissos assumidos pelo governo Obama, o cenário que se vislumbra no governo Trump parece confirmar o debate trazido por Hoffman (2015).

Hoffman (2015) demonstra que não basta construir o consenso científico a respeito da questão, muito embora nada menos que o Painel Intergovernamental para a Mudança do Clima (IPCC) seja o substrato técnico-científico do regime, visto que é preciso, também, construir um consenso social sobre a necessidade de adoção das medidas tendentes à estabilização da temperatura global e que essas medidas passam pela realização de certos esforços e pela aceitação de alguns sacrifícios.

Infelizmente, é difícil conquistar a adesão somente com discurso, e as pessoas ainda consideram a questão das mudanças climáticas como algo abstrato ou para o futuro distante; e parece que será preciso esperar que a humanidade e os agentes da governança global, em todos os níveis, "sintam no bolso e na pele" os efeitos das mudanças climáticas, para que seja construído um consenso mínimo que fortaleça o elemento cognitivo do regime, fundamental para a sua eficácia.

Nesse sentido, é preciso "aproveitar" (como oportunidades) os eventos climáticos extremos que vierem a acontecer relacionados com as mudanças do clima global para, didaticamente, demonstrar à humanidade o que ela pode encontrar pela frente num futuro próximo, caso não se conscientize do problema e da necessidade de adoção das medidas de mitigação, de adaptação e de outras medidas relevantes para enfrentar as mudanças climáticas e o aquecimento global antropogênico.

O relativo sucesso da COP-21 em torno de um novo instrumento vinculante acaba sendo fundamental, não apenas para o futuro do regime, mas também para o futuro da vida no planeta e da civilização humana. Entretanto, a celebração do instrumento, a sua entrada em vigor num cenário temporal que traz a questão climática para a agenda política dos governos, não é de todo significante em termos de resultado do regime. Um novo acordo no regime deve incentivar rearranjos institucionais, o que ainda não se viu na COP-22 de Marrakech, ainda que, basicamente, fosse essa a principal demanda da Conferência de 2016. 
Há alguns desafios próprios do regime que devem ser enfrentados com urgência, tais como decidir a respeito do emprego de sanções para os países que não cumprirem suas metas de redução ou suas obrigações decorrentes do regime jurídico, além das comunicações nacionais, do monitoramento, da transferência de tecnologia e capacitação, do financiamento e da transparência de ação.

\subsection{O encaminhamento da partilha de responsabilidades}

Outro aspecto desafiador relevante, como já visto, está na concretização e na aplicação do princípio (abstrato) das responsabilidades comuns, mas diferenciadas. Como princípio desenvolvido no seio do Direito Ambiental Internacional, a responsabilidade comum, mas diferenciada, carrega em si uma força de convicção inigualável, que constitui a expressão definitiva e irreversível de sua afirmação histórica, filosófica, científica e jurídica.

Em qualquer lugar da Terra em que se emita um grama de GEE, é a atmosfera inteira que está sendo (sobre) carregada com o aumento da concentração desses gases; e sabe-se também que os efeitos das mudanças não serão definidos em função do lugar em que ocorreram as emissões, nem tampouco esses efeitos ficarão restritos a determinados locais (RUIZ, 2012).

Essa falta de determinismo causalista no sistema global climático, especialmente diante do fenômeno da globalização, rompe com todas as soluções tradicionais que o Direito, técnica de decidibilidade de conflitos, pode oferecer: o tradicional esquema da responsabilidade civil e de seus assemelhados, fundado no paradigma do nexo causal, é absolutamente inoperante em sede de mudanças climáticas; é totalmente inconcebível a ideia de que é possível exercer alguma espécie de poder soberano sobre a qualidade, a composição e a movimentação do ar atmosférico da coluna de ar situada acima do território físico do Estado (RUIZ, 2012).

Entretanto, como foi dito acima, não basta o reconhecimento do princípio da responsabilidade comum, mas diferenciada. É preciso concretizá-lo, tirá-lo das alturas da abstração e trazê-lo para o território real sociopolítico de sua aplicação histórica e social.

A partilha Estado a Estado, povo a povo, nação a nação, economia a economia, vulnerabilidade a vulnerabilidade, tecnologia a tecnologia dessa responsabilidade comum será, talvez, o maior desafio da história da 
humanidade até o momento.

E o encaminhamento, a solução dessa partilha, ao que parece, não está ao alcance de um tribunal internacional ou de um organismo supraestatal, tampouco numa disputa de poder soberanista, polarizada e conservadora, muito menos no uso da força bélica.

\subsection{A prática da governança}

Se existe alguma condução nessa solução, ela parte da assunção das vulnerabilidades e dos desafios postos, que somente poderão ser logrados por meio da governança, como técnica e processo para o enfrentamento democrático (com participação multinível), autorregulatório (desde que dotado de eficácia e mais do que somente soft law), institucional (mas não travado nem amarrado, como se encontra) e reflexivo (gerindo os riscos climáticos de forma plástica e dinâmica) desse problema comum e inadiável da humanidade.

Somente a governança poderá apontar a medida concreta e a dimensão real da responsabilidade (e sacrifício) de cada unidade (Estado) nessa totalidade astronomicamente complexa.

Um caminho possível se vislumbra quando a Convenção inova na elaboração de metas de redução das emissões de GEE e, diferentemente da lógica de Quioto, solicita às partes que apontem seus compromissos de redução (INDCs); e esses compromissos autoassumidos tornam-se mandatórios e podem ser cobrados pelos demais envolvidos, não apenas com sanções, mas com a possibilidade de ações e intervenções, seguindo uma estratégia de bottom-up.

Afinal, como bem observam Dubois e Morosini (2016, p. 197) "a consolidação do controle do cumprimento e da sanção do descumprimento são, geralmente, analisadas como fatores que conduzem à melhora da efetividade" dos regimes.

Mas isso não basta! É um trecho de um longo caminho, já que os compromissos individuais de cada Estado, ao se somarem, não garantem que será possível atingir os níveis necessários de emissão para a estabilização climática em $2^{\circ}$ (dois graus) acima dos níveis pré-industriais.

Um próximo passo, em tal cenário, seria definir critérios para cortes, e isso deveria ser feito numa pintura adicional à ConvençãoQuadro por meio da governança, para que todos os países "contribuam proporcionalmente, de forma equitativa" - suficiente e necessária para 
estabilizar o sistema climático.

As ferramentas à disposição seriam a negociação, o diálogo, a transparência de ação, a cooperação (capacitação, financiamento, transferência de tecnologia), entre outras mais compatíveis com a prática da governança. E outro ponto importante sobre o regime é sua plasticidade funcional e adaptabilidade.

Com base no princípio da precaução, encontram-se a avaliação e a revisão permanentes e a construção de consenso entre os países acerca do uso combinado das estratégias de enfrentamento das mudanças climáticas, a saber: a) o planejamento territorial para adaptação às mudanças climáticas (uso do solo nas regiões costeiras, instalação de novos empreendimentos nessas regiões, como portos estaleiros, entre outros), entre outras medidas de adaptação; b) a descarbonização da economia, a criação de "empregos verdes" e cortes nas emissões de GEE, nos vários setores; c) o desenvolvimento e a utilização de tecnologia como a geoengenharia, sem que qualquer uma dessas estratégias de enfrentamento seja simplesmente descartada. Elas devem, ao contrário, ser integradas e produzir sinergia, de forma que o uso combinado dessas estratégias produza mais efeitos no enfrentamento das mudanças climáticas do que o uso isolado delas, propiciando ganho de eficiência.

Mesmo que a Convenção-Quadro tenha sucesso em atingir tempestivamente o seu objetivo final de estabilizar o sistema climático em torno de um nível de emissão de GEE e de um aumento da temperatura global razoavelmente seguro e tolerável, ainda assim é preciso observar que o regime das mudanças climáticas pode não ser suficiente para evitar a possível ocorrência de eventos catastróficos ou mesmo sistêmicos, provenientes de um realinhamento ou de novo estado de equilíbrio da biosfera.

\subsection{As fronteiras planetárias}

Essa ideia se compatibiliza com a visão proposta por Rockström et al. (2009), a respeito das chamadas fronteiras planetárias, que, ao serem ultrapassadas, poderiam colocar em risco o equilíbrio ecológico em nível planetário: If one boundary is transgressed, then other boundaries are also under serious risk. (p. 474) ${ }^{9}$.

9 Se uma das fronteiras planetárias é ultrapassada, então as demais fronteiras estão em sério risco. (Tradução do autor) 
Conforme Viola e Franchini (2012), a noção de fronteiras planetárias aparece como uma nova forma de abordar a sustentabilidade, não já de forma isolada e localizada como a abordagem ambiental clássica, mas de forma global, sistêmica.

As fronteiras planetárias correspondem a certos limites representados por fatores físicos do ambiente (como o $\mathrm{pH}$ dos oceanos, a concentração de $\mathrm{CO}_{2}$ na atmosfera), ou aparecem como limites de utilização, exploração ou degradação de recursos e bens ambientais dentro dos quais a civilização humana poderia operar com segurança, sem colocar em risco o equilíbrio ecológico planetário.

Essas fronteiras são formadas por nove limites que, ao serem ultrapassados, poderão colocar em risco a estabilidade ambiental mantida durante o último período geológico que antecede a Revolução Industrial, e, consequentemente, deslocar o equilíbrio do sistema global (biosfera), podendo acarretar consequências prejudiciais ou mesmo catastróficas em várias partes do globo terrestre ${ }^{10}$.

Nas palavras de Viola e Franchini (2012, p. 2),

[...] nove fronteiras planetárias são identificadas, sete ${ }^{11}$ das quais são passíveis de serem quantificadas: mudança climática; acidificação dos oceanos; ozônio; ciclo biogeoquímico do nitrogênio e fósforo; uso da água doce; mudanças no uso da terra; biodiversidade; poluição química; e concentração de aerossóis na atmosfera. Três dessas nove fronteiras planetárias já foram ultrapassadas: mudança climática, taxa de perda de biodiversidade e ciclo do nitrogênio.

Como se pode observar, juntamente com o acréscimo de calor decorrente do balanço entre a radiação solar que entra no planeta e a energia que o planeta libera no espaço, a concentração de GEE na atmosfera por causa dos lançamentos antropogênicos desde a era pré-industrial já teria ultrapassado os níveis considerados seguros para a manutenção da estabilidade do sistema climático global.

Do mesmo modo, a perda de biodiversidade, quantificada pela taxa de extinção de espécies por milhão de espécies existentes, já pode estar

10 Transcrevem-se as considerações dos cientistas que propuseram a ideia das fronteiras planetárias (PB): [...] Since the Industrial Revolution, a new era has arisen, the Anthropocene [nota 4], in which human actions have become the main driver of global environmental change [nota 5]. This could see human activities push the Earth system outside the stable environmental state of the Holocene, with consequences that are detrimental or even catastrophic for large parts of the world [...]" (2009, p. 474).

11 Atualmente, oito das nove fronteiras planetárias ou (PB) foram quantificadas, restando apenas a quantificação da inserção de novas entidades biológicas. 
colocando em risco a capacidade de resiliência dos ecossistemas, ou seja, sua capacidade para recuperar-se e manter-se estrutural e funcionalmente equilibrado diante de pressões externas, como a ação do homem.

A remoção de nitrogênio molecular da atmosfera, para ser utilizado pelo homem, quantificada em milhões de toneladas por ano removidas da atmosfera, já ultrapassou em muito o limite anual considerado seguro (ROCKSTRÖM et al., 2009, p. 473/4).

Além desses três limites globais, atualmente, há notícia de que já foi ultrapassada uma quarta fronteira planetária: a das mudanças no uso da terra (STEFFEN et al., 2015). Dessa forma, o percentual da cobertura original do planeta convertido para uso do homem (lavoura) já teria ultrapassado o limite prudencial de $15 \%$ da cobertura original.

Adotando-se a abordagem das fronteiras planetárias dentro das quais a humanidade poderia operar com segurança, formadas por nove limites cujas capacidades de suporte planetário, ao serem ultrapassadas, poderão colocar em risco a estabilidade e o equilíbrio do sistema global (biosfera), é preciso começar a pensar num mecanismo de governança integrador de regimes, capaz de articulá-los entre si.

A governança ambiental global (embora ainda deficitária) mostrase como a ferramenta mais adequada para enfrentar a questão dos problemas comuns da humanidade, especialmente os problemas ambientais, mas entende-se que a governança, para agir eficazmente, precisa da quebra de paradigmas conservadores (VIOLA; FRANCHINNI, 2012), assim como de um mínimo de ordem e estabilidade, ou seja, de um conjunto de condições e de instituições, que são incompatíveis com um retorno à barbárie global, a um conflito armado ou a posturas absolutamente unilaterais, de arrogância e intolerância.

\section{CONCLUSÕES}

É fato o avanço do Regime das Nações Unidas para a Mudança Climática, a partir da entrada em vigor do Acordo de Paris; e, diante do reconhecimento de que a fronteira climática planetária já foi ultrapassada e de que a humanidade não opera mais em um espaço seguro em relação à estabilidade do sistema climático, é imprescindível que esse regime gere resultados.

Os esforços ao longo de quase 25 anos de negociações, no âmbito do regime internacional, em torno da complexa distribuição das 
responsabilidades comuns, mas diferenciadas, que cabem a cada país no esforço de mitigação de emissões, tiveram resultados pouco eficientes até o momento, ainda que não possam ser desprezados. A forte expectativa gerada com a nova etapa aberta na agenda mundial, a partir de 2016, não desconhece que as decisões tomadas ainda são insuficientes para garantir o objetivo de estabilização climática, porém demonstram a vitalidade de um processo complexo de negociação multilateral, que já apresentava sinais desanimadores.

Diante da abordagem de fronteiras planetárias interconectadas, faz-se necessário destacar que não basta vencer os desafios de celebrar e, depois, implantar e cumprir um acordo global de redução de emissões de GEE sem que também se promova uma eficaz governança no combate à desertificação, ao desmatamento e à degradação florestal, à conversão da cobertura vegetal natural, à perda da biodiversidade e da acidificação dos oceanos, na diminuição da remoção de nitrogênio atmosférico, do consumo excessivo de recursos hídricos, da poluição química e do lançamento de aerossóis na atmosfera.

\section{REFERÊNCIAS}

ACORDO DE PARIS SOBRE O CLIMA. Disponível em: <https:// nacoesunidas.org/acordodeparis/>. Acesso em: 2 jan. 2017.

BRASIL. Decreto n. 2.652, de $1^{\circ}$ de julho de 1998. Promulga a ConvençãoQuadro das Nações Unidas sobre Mudança do Clima, assinada em Nova York, em 9 de maio de 1992. In: SENADO FEDERAL (Ed.). Protocolo de Quioto e legislação correlata. Brasília: Secretaria Especial de Editoração e Publicações, 2004. p. 65-88.

BRASIL. Pretendida Contribuição Nacionalmente Determinada (Indc) Para Consecução do Objetivo da Convenção-Quadro das Nações Unidas sobre Mudança do Clima. Disponível em: <http://www.itamaraty.gov.br/ images/ed_desenvsust/BRASIL-iNDC-portugues.pdf $>$. Acesso em: $7 \mathrm{dez}$. 2016.

CAMARGO, Luis Antonio de. Os regimes internacionais enquanto ações de governança global. In: COSTA E SILVA, A; ARAÚJO, E.L (coord.). Direito ambiental temas polêmicos. Curitiba: Juruá, 2015, p. 85/92. 
CONVENÇÃO-QUADRO DAS NAÇÕES UNIDAS SOBRE MUDANÇA DO CLIMA. Disponível em: <http://www.planalto.gov.br/ccivil_03/ decreto/D2652.htm>. Acesso em: 2 jan. 2017.

DUBOIS, Sandrine Maljean; MOROSINI, Fabio Costa (Trad.). Mudanças climáticas: os desafios do controle do direito internacional ambiental e do Protocolo de Kyoto em particular. Revista Veredas do Direito, v. 13, n. 26, p. 195-210, maio/ago. 2016.

FARIAS, Valeria Cristina e REI, Fernando. De Berlim a Paris: a conferência das partes como espaço para o multilateralismo climático. In: GRANZIERA, M.L.M. e REI, F. (coord.). O futuro do regime internacional de mudanças climáticas: aspectos jurídicos e institucionais. Santos: Edital Livros Produções Editoriais, 2015, p. 97/120.

GONÇALVES, Alcindo. Regimes Internacionais como ações de governança global. Revista Meridiano, v. 12, n. 125, maio/jun. 2011.

GONÇALVES, Alcindo. Impasse nas Negociações sobre Mudança Climática. Política Externa, v. 23, n. 3, jan./mar. 2015, p. 87-103.

HOFFMAN. Andrew J. How culture shapes de climate change debate. Standford: Standford University Press, 2015.

MATO GROSSO. MT assina declaração de esforços conjuntos para desmatamentozero. Disponível em:<http://www.mt.gov.br/-/governador-eministra-assinam-declaracao-de-esforcos-conjuntos-para-desmatamentozero>. Acesso em: 26 dez. 2016.

MORE, R.F.. A segurança ecológica como princípio de segurança coletiva. Disponível em: <http:/www.more.com.br/artigos/ Seguran\%FEa\%20ecologica.pdf>. Acesso em: 2 ago. 2017.

NAÇÕES UNIDAS. Acordo de Paris. Disponível em: <https:// nacoesunidas.org/wp-content/uploads/2016/04/Acordo-de-Paris.pdf $>$. Acesso em: 2 jan. 2017.

REI. Fernando; CUNHA, Kamyla. O Brasil e o regime internacional de mudanças climáticas. In: GRANZIERA, M.L.M. e REI, F. (coord.). $O$ futuro do regime internacional de mudanças climáticas: aspectos jurídicos e institucionais. Santos: Edital Livros Produções Editoriais, 2015, p. 17/34. 
ROCKSTRÖM et al., A safe operating space for humanity. Nature, v. 461|24 September 2009, p. 472-75.

RUIZ, José Juste. El régimen internacional para combatir el cambio climático en la encrucijada. In: GILES CARNERO, R. (coord.). Cambio climático, energia y derecho internacional: perspectivas de futuro. Madrid: Aranzadi, 2012, p. 37-49.

STEFFEN W. et al., Planetary boundaries: Guiding human development on a changing planet. Science 13 february 2015, v. 347 n. 6223.

VIOLA, E.; FRANCHINI, M. Sistema internacional de hegemonia conservadora: o fracasso da Rio +20 na governança dos limites planetários. Ambiente \& Sociedade, v.15 n. 3, sept./dec. 2012.

YOUNG, Oran. Institutional dynamics: Emergent patterns in international environmental governance. Cambridge, MA: MIT Press, 2010.

Artigo recebido em: 02/02/2017. Artigo aceito em: 07/08/2017.

\section{Como citar este artigo (ABNT):}

REI, Fernando Cardozo Fernandes; GONÇALVES, Alcindo Fernandes; SOUZA, Luciano Pereira de. Acordo De Paris: reflexões e desafios para o regime internacional de mudanças climáticas. Veredas do Direito, Belo Horizonte, v. 14, n. 29, p. 81-99, maio/ago. 2017. Disponível em: <http:// www.domhelder.edu.br/revista/index.php/veredas/article/view/996>. Acesso em: dia mês. ano. 